\title{
Testing of coupling beams with equal end rotations maintained and local joint deformation allowed
}

\author{
A. K. H. Kwan and Z. Z. Zhao
}

The strength and ductility of the coupling beams in coupled shear walls can significantly affect the nonlinear behaviour and earthquake resistance of the whole building structure. However, although extensive testing of coupling beams has been performed, the boundary conditions-that the rotations at the two ends of a coupling beam are equal and that local deformation occurs at the beam-wall joints, which could have substantial influence on the test results-have not been correctly simulated. Herein, a new method of testing reinforced concrete coupling beams that ensures equal rotations at the ends of the beam specimen and takes into account local deformation at the beam-wall joints is developed. The method has been successfully applied to test typical reinforced concrete coupling beams with relatively small span/depth ratios and proven to be suitable for studying the post-peak behaviour and failure characteristics of short coupling beams. Test results obtained so far indicate that reinforced concrete coupling beams with small span/depth ratios behave quite differently from ordinary beams in frame structures and that the local deformation at beam-wall joints is quite substantial. Complete load-deflection curves have been acquired and the strength and ductility of the coupling beams evaluated.

\section{INTRODUCTION}

Shear walls are widely used for tall concrete buildings. Due to the presence of regular door or window openings, a shear wall is often divided into smaller wall units coupled by beams formed between openings. Under lateral load, the shear is resisted by the wall units themselves while the overturning moment is resisted jointly by the bending action of the wall units and the couple formed from axial forces developed in the wall units. During a severe earthquake, if the coupling beams are very strong, the wall units might fail due to the large axial forces and bending moments induced in them without prior yielding of the coupling beams. As the wall units are taking vertical loads and are the major lateral load-resisting elements, this could endanger the safety of the building and render the repair after earthquake very difficult. On the other hand, if the coupling beams are not too strong, they will yield and dissipate the vibration energy before the walls yield, thereby protecting the walls from being damaged. A coupled shear wall structure with its coupling beams designed to yield before the walls yield acts like a sandwiched beam with a damping core and is thus particularly good for resisting earthquakes.

The non-linear behaviour of coupled shear walls has been studied both theoretically ${ }^{1-3}$ and experimentally. ${ }^{4-6}$ Basically, all studies led to the conclusion that the strength and ductility of the coupling beams have major influences on the non-linear behaviour and earthquake resistance of the coupled wall structures. Particularly, plastification of the coupling beams before the walls yield could significantly improve the ductility of the coupled wall structures. However, after plastification, the coupling beams would be subjected to certain ductility demand depending on the strength of the coupling beams, being higher when the beams are relatively weak and lower when the beams are relatively strong. As a general rule, Aristizabal-0choa ${ }^{5}$ has suggested that both overcoupling (coupling beams being too strong), which causes the walls to fail without prior yielding of the coupling beams, and undercoupling (coupling beams being too weak), which causes the ductility of the coupling beams to be exhausted before the walls yield, should be avoided. So far, most theoretical studies are based on simplified elasto-plastic models for the coupling beams. There is still no universally accepted non-linear structural model that could take into account the actual load-deflection behaviour and limited ductility of the beams.

From the previous studies, it is evident that both the strength and ductility of the coupling beams need to be considered in the earthquake-resistant design of coupled wall structures. Since the strength of coupling beams can be adjusted simply by changing the beam size and reinforcement layout, providing appropriate strength to the coupling beams presents no particular difficulties. However, providing sufficient ductility to the coupling beams is generally quite difficult because most coupling beams are relatively short and deep, and tend to fail in shear. There is also no reliable method for predicting the ductility of coupling beams. To deal with this ductility design problem, it is first necessary to measure the complete loaddeflection curves of the coupling beams so that their ductility can be evaluated. Then, when sufficient data are available, a method for predicting the ductility of coupling beams should be developed so as to allow ductility analysis. Since the loaddeflection curves are dependent on the failure mode, a good 
understanding of the possible failure mechanisms of coupling beams is also necessary.

The need to investigate the non-linear behaviour and analyse the strength and ductility of coupling beams has attracted the attention of many researchers. Early in 1971, Paulay ${ }^{6}$ had found that although coupling beams with span/depth ratios $>2.0$ behave like ordinary beams in frame structures, coupling beams with span/depth ratios $<2 \cdot 0$ behave quite differently. After the appearance of diagonal cracks, a coupling beam with span/depth ratio $<2 \cdot 0$ will, on being subjected to further loading, gradually elongate causing all longitudinal reinforcement to be in tension throughout the whole length of the beam. Such behaviour differs significantly from that predicted by the ordinary beam theory and hence short coupling beams should not be treated as ordinary beams.

Regarding the mechanism of shear resistance, there is so far no generally accepted theory. According to Fenwick and Paulay, ${ }^{4}$ the shear mechanism may be modelled as a combination of diagonal strut action and truss action. In the diagonal strut action, the concrete struts formed between diagonal cracks act against the two adjacent walls in the diagonal direction. The transverse component of the compressive force in the struts provides the shear resistance while the longitudinal component pushes the adjacent walls apart leading to elongation of the beam and tension in all longitudinal reinforcement. In the truss action, the inclined struts formed in the beam work together with the transverse shear reinforcement to transfer the shear from one end of the beam to the other. Roughly, the diagonal strut action dominates in short coupling beams but as the span length increases, the truss action may become more important.

Conventionally reinforced coupling beams may fail by bending like ordinary beams or by shear in three different modes: shear-tension, shear-compression and shear sliding. ${ }^{7}$ Sheartension failure is caused by diagonal tension failure of the concrete at the centre and yielding of the transverse reinforcement. This kind of failure can be avoided by increasing the transverse reinforcement and limiting the design shear load acting on the beam. Shear-compression failure is caused by crushing of the concrete at the point where the diagonal struts in the beam act against the walls after yielding. Such failure cannot be prevented by increasing the transverse reinforcement but may be avoided by limiting the design shear acting on the beam. Shear-sliding failure is caused by sliding along transverse cracks at the beam-wall joints, which are formed by bending cracks cutting through the whole section due to load reversal. Since the sliding surfaces are parallel to the transverse reinforcement, putting in more transverse reinforcement will not deter this kind of failure.

It can be seen from the above that the most important aspects of coupling beam design are the prediction of failure mode, analysis of load-deflection curve and evaluation of ductility. Unfortunately, there is still no commonly accepted structural model or even empirical formula that can be used for such purposes. The authors have reviewed the previous experimental studies ${ }^{8}$ and tried to develop a non-linear structural model for conventionally reinforced concrete coupling beams but found that the available test results are not yet sufficient. Moreover, there seem to be several shortcomings with the previous test methods, which will be discussed in detail in the following section. To resolve the problems involved, a new test method has been developed in this study. Its main features are as follows.

(a) Unlike previous test methods, which allow the ends of the beam specimen to rotate without control, the rotations of the two ends of the beam specimen are controlled to be equal.

(b) A part of the wall is attached to each end of the beam specimen to allow for local wall deformation near the beam-wall joints.

(c) The test is conducted under displacement control so that the post-peak behaviour may be investigated and the complete load-deflection curve may be obtained for ductility evaluation.

\section{REVIEW OF PREVIOUS TEST METHODS}

In most previous test methods, such as those adopted by Paulay, ${ }^{6}$ Wang et al. ${ }^{9}$ and Tassios et al., ${ }^{10}$ the coupling beam specimens were tested by subjecting them to prescribed loading acting at their ends. In order to produce equal contraflexural moments at the two ends of the beam specimen, the line of action of the applied load was aligned to pass through the centre of the beam specimen, which was assumed to remain a point of contraflexure throughout the test. These test methods very well simulated the loading conditions of a real coupling beam before the beam started to crack. However, after the beam had cracked, since there might be more cracks near one of its ends, the distribution of beam stiffness and deformation might no longer be symmetric about the centre of the beam. Between the two beam-wall joints, greater deformation would occur at the more seriously cracked joint and consequently one end of the beam specimen might rotate more than the other. This phenomenon was more serious after the peak load was reached and thus at the post-peak stage, the rotations at the two ends of the beam could be very different, as had been observed by Paulay and Binney ${ }^{11}$ and Li and Li. ${ }^{12}$

In a real coupled wall structure, however, the shear load is applied to a coupling beam through relative shear displacement of the two walls at its ends. Since the walls are constrained by floor slabs to deflect together, they deflect laterally by the same amount at the same floor level. As the rotations of the walls are equal to the rate of change of lateral deflection with height, the walls also rotate by the same amount at the same floor level. Hence, the rotations of the two ends of a coupling beam should be equal, as illustrated in Fig. 1. Since the end rotations were not controlled to be equal in the previous test methods, the displacement boundary conditions had not been properly simulated.

There were two other problems with the previous test methods. Firstly, since the loads were applied directly at the beam-wall joints, the local deformation at the joints had not been properly allowed for. In some tests, the walls were even thickened to avoid local failure at the loading points and thus the full amount of local joint deformation could never take place. In a real coupled wall structure, however, significant local deformation occurs at the beam-wall joints. At the elastic stage, the additional beam deflection due to joint deformation 


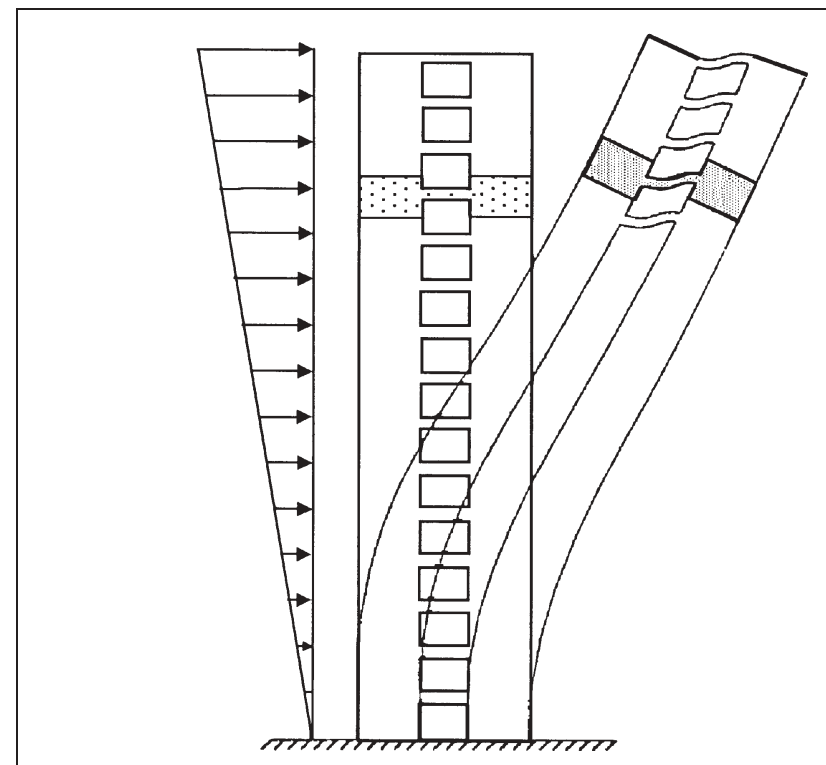

(a)

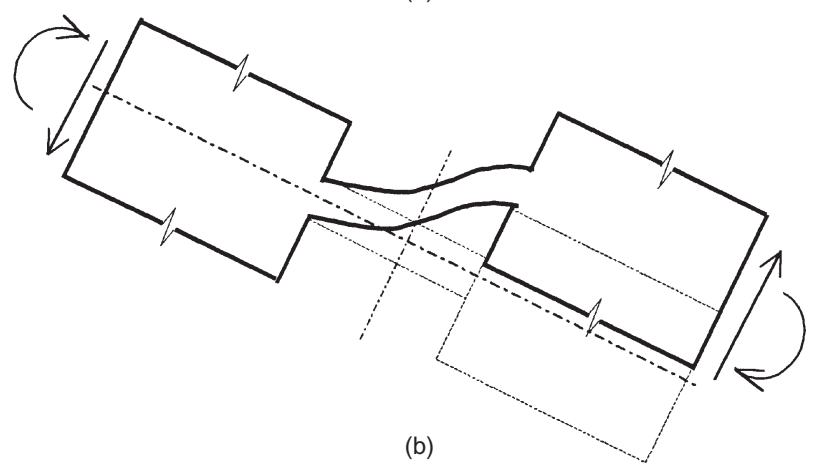

Fig. I. Deflection pattern of coupling beams in a real coupled wall structure: (a) deflection of wall structure; (b) deflection of coupling beam

is roughly equivalent to an extension of the beam at each end of about $0 \cdot 3$ times the beam depth. ${ }^{13}$ Beyond the elastic stage, little study has been carried out but as the failure zones of the beam often extend well into the walls, it is likely that the cracking and crushing of the concrete and the bond-slip and yielding of the reinforcement bars in the walls near the joints could have significant effects on the behaviour of the coupling beam. Additionally, since the end rotations of the beam specimen were not controlled to be equal, the shear deflection of the coupling beam could not be properly defined. As a result, the load-deflection curves obtained, especially their descending branches, could be quite misleading. Moreover, since the shear deflection was not well-defined, it was difficult to carry out the test under displacement control.

Among the existing test methods, the one developed at the Portland Cement Association (PCA), whose set-up is shown in Fig. 2(a), is probably the best in simulating the displacement boundary conditions of the coupling beams. ${ }^{14}$ The test specimen used by PCA consisted of two coupling beams connected to two abutment walls. Load was applied to one of the abutment walls with its line of action passing through the centres of the coupling beams. Provided the two coupling beams are identical and they elongate by the same amount at all times, the two abutment walls should remain parallel throughout the test and the rotations at the ends of the coupling beams should be equal. Fairly large parts of the walls have been attached to the ends of the coupling beams and therefore any possible effects of the local deformation at the beam-wall joints during the elastic and inelastic stages should have been allowed for. However, the overall size of the specimen, which included two coupling beams and two abutment walls, was quite large (total length of specimen $=3.35 \mathrm{~m}$ ), even though the coupling beams tested were only $169 \mathrm{~mm}$ deep and $423 \mathrm{~mm}$ long (about 1/3 scale). Only relatively slender coupling beams with span/depth ratios equal to or greater than $2 \cdot 5$ had been tested using this method.

When studying experimentally the non-linear behaviour of reinforced concrete, it is important to test models with as large a scale as possible in order to avoid scale effects. To test largerscale models, it is better to test one coupling beam at a time so that for a given specimen size (often limited by space and capacity of equipment used) the beam can be made as big as possible. A test method for testing one beam at a time while maintaining equal end rotations has been developed at the Building Research Institute (BRI) of Japan. ${ }^{15}$ Its test set-up is shown in Fig. 2(b). The main feature of this set-up is that a rotation restraining mechanism has been installed to ensure that the upper end of the beam specimen remains parallel to the lower end at all stages. The beam specimens tested were of approximately $1 / 3$ scale. They were generally quite slender having span/depth ratios greater than $3 \cdot 0$. Fairly big end blocks were attached to the two ends of the beam specimen for fixing the specimen to the testing frame. However, the end blocks were designed purely for fixity and did not resemble any parts of the real structure. Hence, the local deformation at the joints between the beam and the rest of structure had not been properly allowed for.

Having reviewed the above test methods, it is concluded that a suitable test method for studying the complete load-deflection behaviour of coupling beams should satisfy the following conditions

(a) the rotations of the two ends of the beam specimen should be controlled to be equal

(b) the local deformation at the beam-wall joints should be allowed for

(c) the test should be conducted under displacement control so that the descending branch of the load-deflection curve may be obtained

(d) the test specimen should have a scale as large as possible.

\section{PROPOSED TEST METHOD}

Figure 3 shows the set-up of the proposed test method. As shown in the figure, the beam specimen is erected with the longitudinal axis of the beam in the vertical direction. It is fixed at one end to a rigid ground beam and connected at the other end to a T-shaped steel loading frame. Shear load is applied to the specimen through the loading frame by a servocontrolled hydraulic actuator, whose loading and support ends are pin-connected to the loading frame and a horizontal reaction frame respectively. The line of action of the applied load is aligned to pass through the centre of the beam 


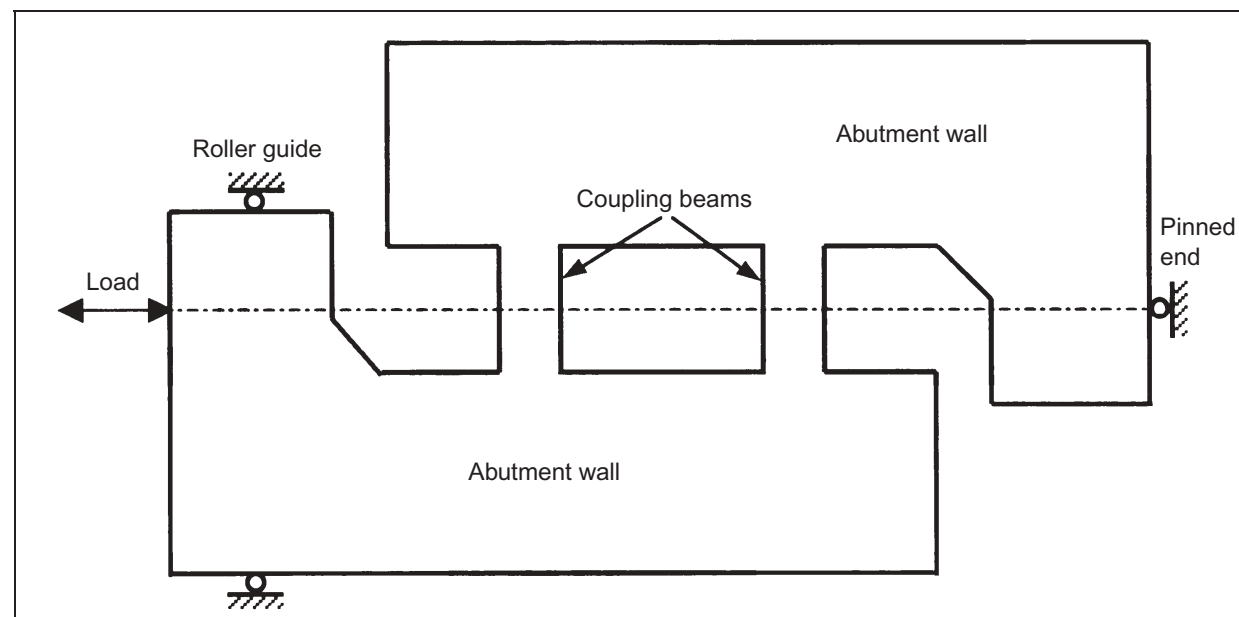

(a)

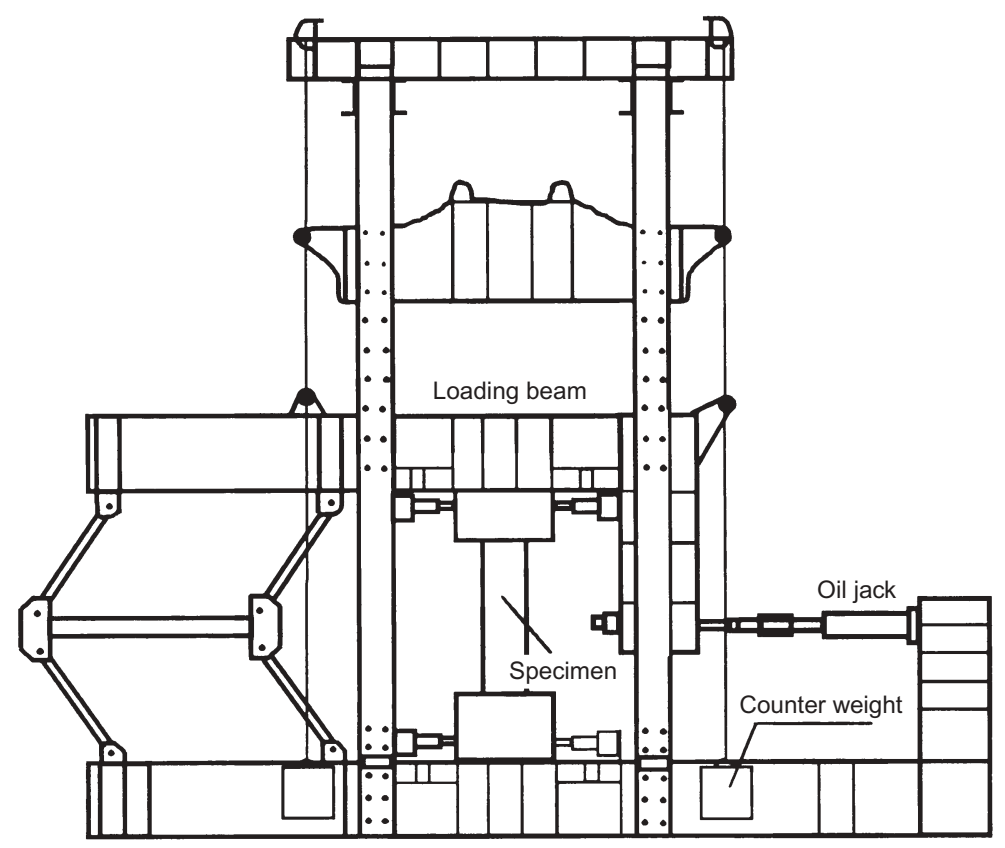

(b)

Fig. 2. Test set-up by: (a) Portland Cement Association; ${ }^{14}$ (b) Building Research Institute

specimen. A rotation restraining mechanism consisting of two parallelogram-shaped pin-jointed trusses is installed to ensure that the rotations of the two ends of the specimen are equal. Out-of-plane movements of the loading frame and the beam specimen are restrained by the provision of roller guides. The self-weight of the loading frame is balanced by a

counterweight through a pulley system. Both monotonic and cyclic loading tests can be carried out using this set-up. All tests are conducted under displacement control.

The beam specimen consists of the coupling beam itself and two end blocks representing parts of the wall panels to which the coupling beam is connected. The following factors are considered in the design of the two end blocks (see Fig. 4).

(a) Since in most cases, the coupling beams and the wall panels have the same thickness, the end blocks, which are there to model beamwall interaction, are designed to have the same thickness as the coupling beams.

(b) As significant local deformation occurs in the walls within distances of about half the beam depth from the beamwall joints, ${ }^{13}$ the end blocks are designed to have a width greater than the beam depth and a depth greater than two times the beam depth to ensure that the local wall deformation is fully accommodated.

(c) Since bond-slip of the rebars at the beam-wall joints can affect the behaviour of the coupling beams, the longitudinal reinforcement bars are provided with generous anchorage lengths of not less than 50 times the bar diameter into the end blocks.

(d) In order to avoid interfering with the beam-wall interaction and allow for the local deformation at the beam-wall joints, the loads must not be applied to the beam specimen at anywhere close to the beam-wall joints. In the present study, the loads are applied to the beam specimen at the far end edges of the end blocks, which are at distances of greater than the beam depth from the joints.

The proposed test method resembles the one developed by BRI. ${ }^{15}$ In either method, a rotation restraining mechanism is provided to ensure that the rotations of the two ends of the beam specimen are equal. However, the positions of the rotation restraining mechanisms are not the same in the two methods. In BRI's test set-up, the rotation restraining mechanism is located at one side of the beam specimen and connected to an extension of the steel beam that transmits the applied load to the beam specimen. This has the problem that any flexural deflection of the steel beam could affect the effectiveness of the rotation restraining mechanism. To avoid such a problem, it is better to connect the ends of the rotation restraining mechanism directly to the ends of the beam specimen, as has been done in the present test method. Another major difference is in the design of the beam specimen. The 


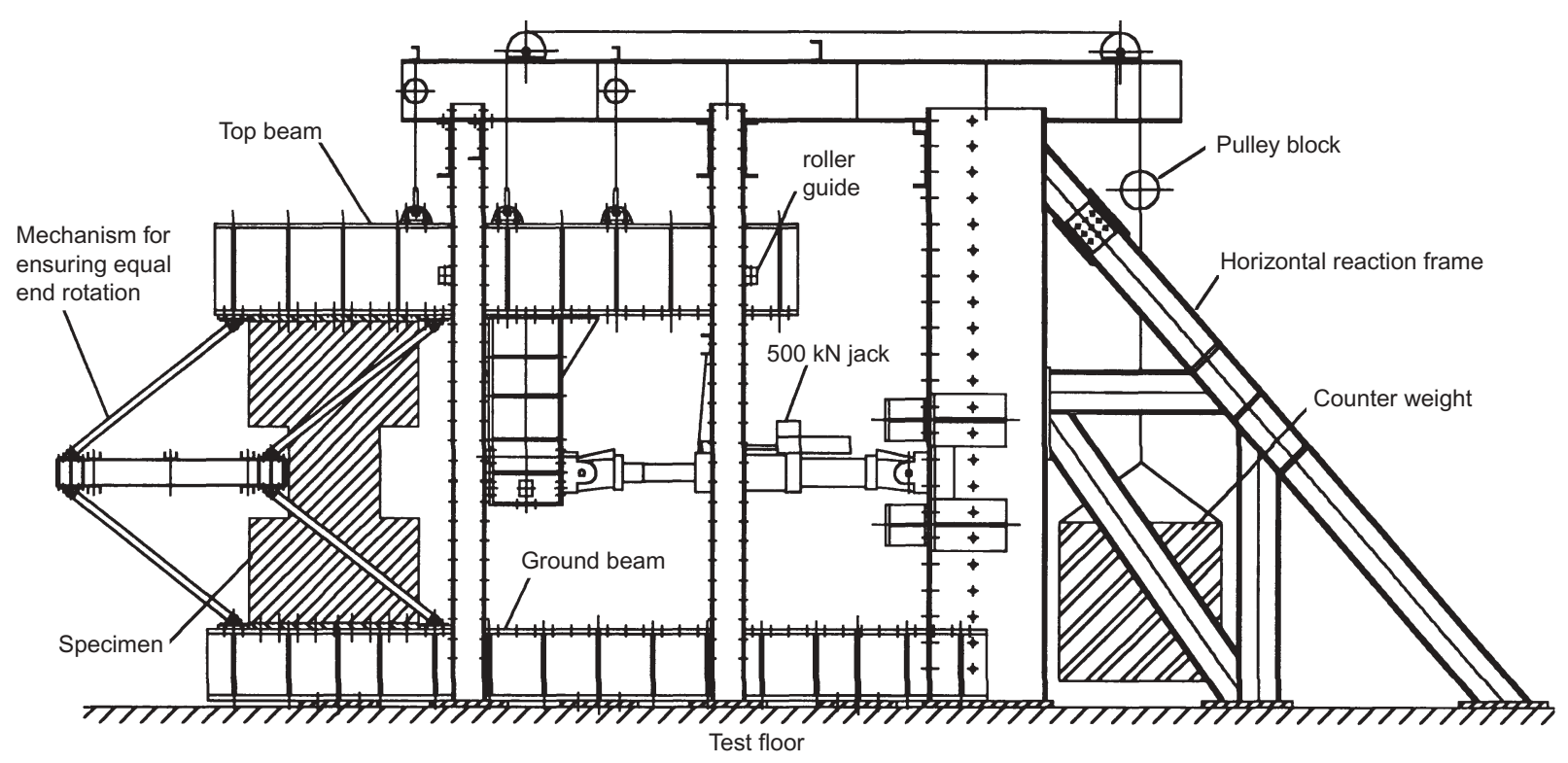

Fig. 3. Proposed test set-up

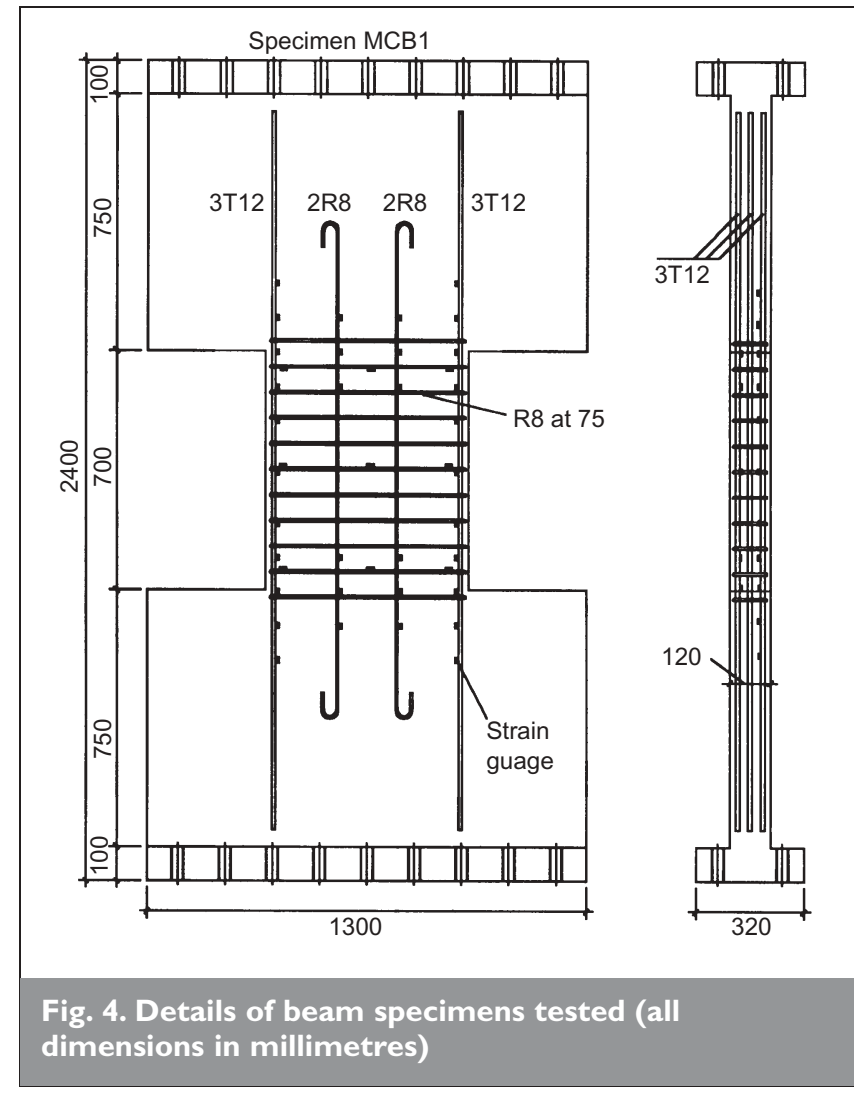

beam specimens tested by BRI were relatively slender and no allowance for the local joint deformation had been made in the design of their end blocks. In this study, however, the beams tested are relatively short and deep and full allowance of the local joint deformation has been made in the end block design.

\section{EXPERIMENTAL PROGRAMME}

\section{I. Specimen design}

As a start, only conventionally reinforced coupling beams (coupling beams with only longitudinal and transverse reinforcement provided) were tested. Fig. 4 shows the details of the beam specimens. The specimens were basically $1 / 2$ scale models of typical coupling beams. The thickness and clear span of all the beams were fixed at 120 and $700 \mathrm{~mm}$ respectively. Different span/depth ratios were obtained by varying the depth of the beam. Four beam specimens with span/depth ratios of $1 \cdot 17,1 \cdot 40,1.75$ and 2.00 and other structural parameters as listed in Table 1 were made for testing. At each end of the specimen, a rectangular end block $(1300 \mathrm{~mm} \times 850 \mathrm{~mm})$ having the same thickness as the beam and representing part of the wall connected to the beam was cast integrally with the beam as part of the specimen. Unlike ordinary beams in which longitudinal reinforcement bars are placed only at the top and bottom of the beam sections, additional longitudinal reinforcement bars had been added at mid-depth of the beam sections. All longitudinal reinforcement bars were provided with generous anchorage into the end blocks. At the far end edge of each end block, a flange $320 \mathrm{~mm}$ wide and $100 \mathrm{~mm}$ thick prefabricated with 18 boltholes was provided for connecting the specimen to the testing frame.

\subsection{Materials}

The concrete used was made from crushed granitic aggregate having a maximum size of $10 \mathrm{~mm}$. Its water/cement ratio was set at 0.59. All beam specimens were cast with their planes lying horizontally. They were moist-cured for seven days and thereafter stored under ambient conditions. Along with each beam specimen, three $150 \mathrm{~mm} \times 300 \mathrm{~mm}$ cylinders and three $150 \mathrm{~mm}$ cubes were cast, cured side by side with the beam specimen and tested at the same age. The average cube and cylinder strengths of the concrete were 52.5 and $40.9 \mathrm{MPa}$ respectively.

High-yield deformed bars were used for the longitudinal reinforcement placed at the top and bottom of the beam sections, whereas mild steel plain round bars were used for the additional longitudinal reinforcement placed at mid-depth of the beam sections and the transverse reinforcement. The high- 


\begin{tabular}{|lcccc|}
\hline Model No. & $\begin{array}{c}\text { Span/depth } \\
\text { ratio }\end{array}$ & $\begin{array}{c}\text { Top and bottom } \\
\text { longitudinal } \\
\text { reinforcement }\end{array}$ & $\begin{array}{c}\text { Additional longitudinal } \\
\text { reinforcement }\end{array}$ & $\begin{array}{c}\text { Transverse } \\
\text { reinforcement }\end{array}$ \\
\hline MCBI & $1 \cdot 17$ & $3 T I 2$ & $4 R 8$ & R8 @ 75c/c \\
MCB2 & 1.40 & $2 T 12+$ T8 & $4 R 8$ & R8 @ 75c/c \\
MCB3 & 1.75 & $2 T I 2$ & $2 R 8$ & R8 @ 75c/c \\
MCB4 & 2.00 & TI2 $+2 T 8$ & $2 R 8$ & R8 @ 75c/c \\
\hline
\end{tabular}

Notes: $\mathrm{T}$ denotes high-yield deformed bars while $\mathrm{R}$ denotes mild steel plain round bars.

Equal amounts of longitudinal reinforcement were provided at the top and the bottom of the beam section.

The additional longitudinal reinforcement was provided near mid-depth of the beam section.

Table I. Structural parameters of beam specimens tested
However, after the longitudinal reinforcement bars had started to yield, the crack patterns of the four beam specimens began to change. In specimen MCB1, which has the smallest span/ depth ratio, a diagonal shear crack appeared immediately after the longitudinal reinforcement bars had started to yield. The shear crack divided the beam into two triangles interconnected by the transverse reinforcement bars. As the yield bars were of two sizes. Those with $12 \mathrm{~mm}$ diameter had yield and ultimate strengths of 525 and $636 \mathrm{MPa}$ respectively while those with $8 \mathrm{~mm}$ diameter had yield and ultimate strengths of 517 and $717 \mathrm{MPa}$ respectively. On the other hand, the mild steel bars were all of size $8 \mathrm{~mm}$ and had yield and ultimate strengths of 336 and $440 \mathrm{MPa}$ respectively.

\subsection{Deflection and strain measurements}

More than 30 linearly variable differential transducers (LVDTs) were mounted on each coupling beam specimen to measure the lateral deflection, axial elongation, shear and flexural deformations, and joint deformation of the beam specimen. Some LVDTs were installed on an isolated frame to measure the absolute deflection of the specimen while others were mounted directly on the specimen to measure the deformations of the beam itself and the joints. Fig. 5 shows the layout of the LVDTs installed. About 50 electrical resistance strain gauges were glued on selected reinforcement bars to measure the strains developed in the steel reinforcement. They were to determine the strain distribution along the longitudinal reinforcement and to evaluate the amount of shear force carried by the transverse reinforcement. The locations of the strain gauges are marked on the beam specimen shown in Fig. 4.

\section{EXPERIMENTAL RESULTS}

\section{I. General behaviour}

The crack patterns of the four beam specimens after the tests were completed are depicted in Fig. 6. Before the reinforcement bars in the specimens started to yield, the four specimens had similar crack patterns. In all the specimens, flexural cracks were first observed at the tension corners of the beam-wall joints. As the applied load gradually increased, these flexural cracks extended into the wall panels and then turned to run parallel to the beam-wall interfaces along the transverse reinforcement bars near the beam-wall joints. At the same time, new flexural cracks appeared in the beams at the tension sides of the beams. Upon further loading, many of the flexural cracks formed inside the beams turned to an inclined direction and propagated towards the compression corners at the beamwall joints to become combined flexural and shear cracks.

Meanwhile, numerous fine inclined cracks also appeared in the wall panels.

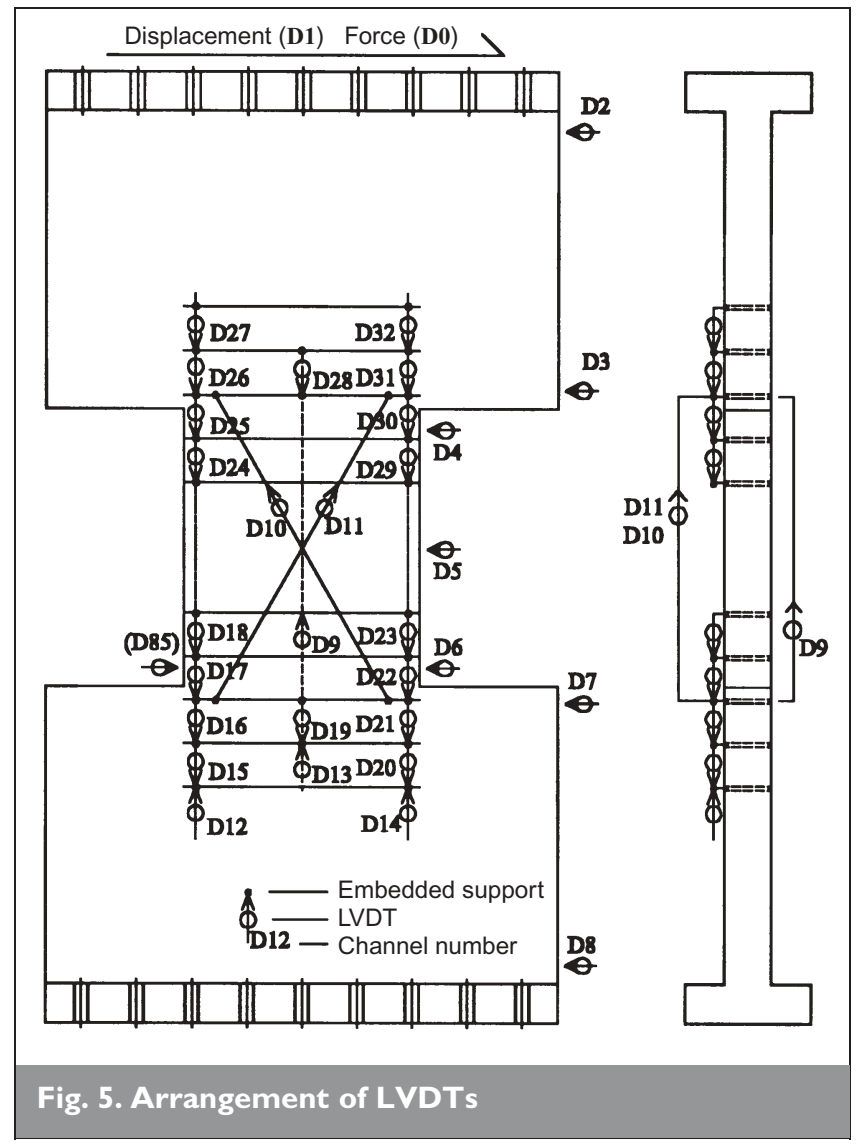

shear deflection of the specimen further increased, the transverse reinforcement bars also yielded and the diagonal shear crack opened up quickly. Eventually, when the width of the diagonal shear crack reached about $10 \mathrm{~mm}$, the concrete at the compression corners of the beam was crushed and the beam specimen failed in shear.

In specimen MCB2, which has a slightly larger span/depth ratio than MCB1, a diagonal shear crack also appeared after the longitudinal reinforcement bars had yielded but at a much later time when the deflection of the beam was almost twice the deflection at yield (the deflection when the longitudinal reinforcement started to yield). This crack gradually developed in length and width but never became critical. On the other 


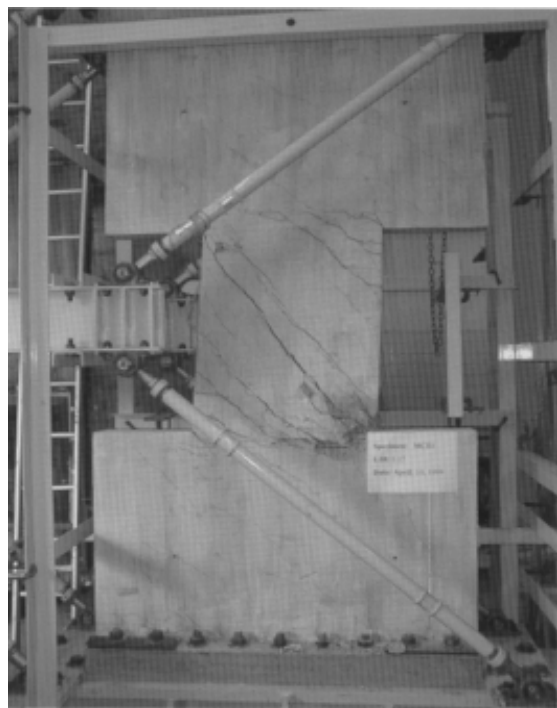

(a)

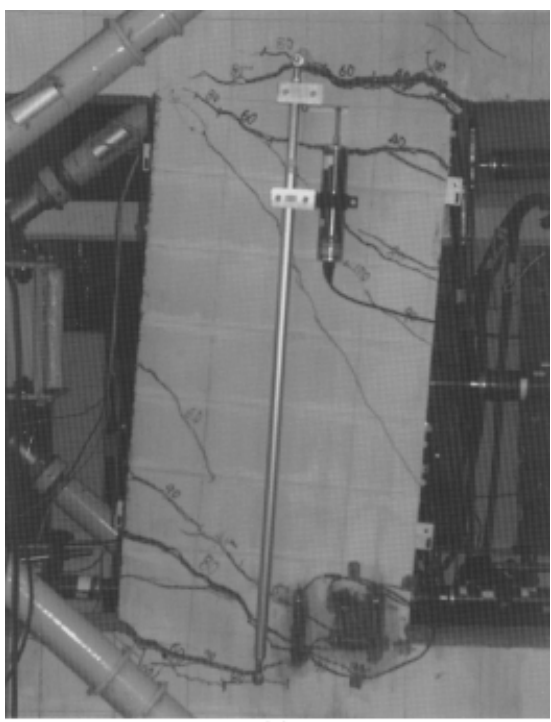

(c)

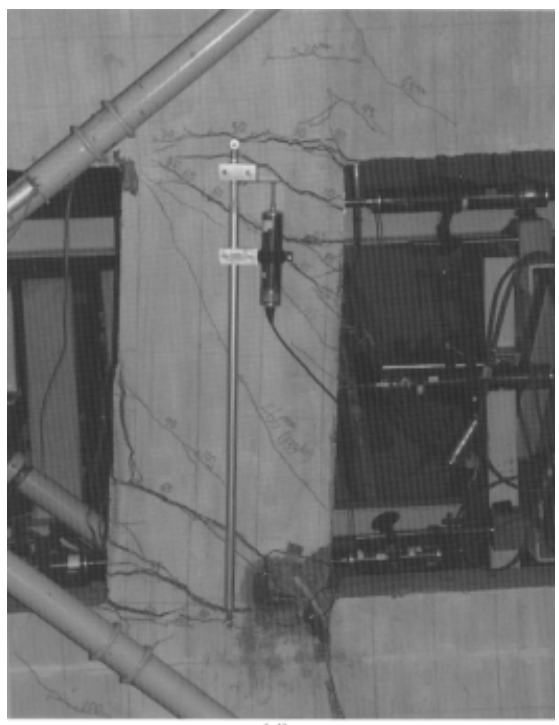

(d)

Fig. 6. Crack patterns and failure modes of the beam specimens: (a) MCB I (shear tension failure); (b) MCB2 (bending failure); (c) MCB3 (bending failure); (d) MCB4 (bending failure)

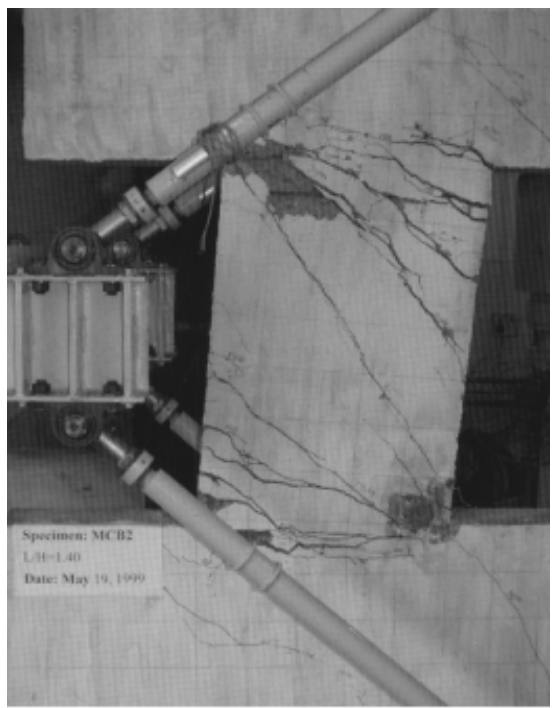

(b)

reinforcement bar was broken before the load-resisting capacity of the specimen had dropped to less than 85\% of the peak load and the test was stopped without reaching the 'ultimate' state at which the load-resisting capacity dropped to $85 \%$ of the peak load.

\subsection{Load-deflection characteristics}

The load-deflection curves of the four beam specimens are plotted in Fig. 7. It should be noted that the deflections used for plotting these loaddeflection curves were the relative shear displacements of the beam specimens measured along the far end edges of the end blocks at the ends of the specimens and thus they included the deflections of the beams themselves and the deflections due to local deformation at the beamwall joints. It is seen that the load-deflection curve of MCB1, which failed in shear, has no obvious yield point. In contrast, the load-deflection curves of the other beam specimens, which failed in flexure, have obvious yield points at deflections of around 4 to $6 \mathrm{~mm}$. From the figure, it can also be seen that MCB1 had the highest strength but it also failed more abruptly. The other beam specimens, MCB2, MCB3 and MCB4, had successively lower strengths

hand, the flexural cracks at the beam-wall joints and the combined flexural and shear cracks at the tension sides of the beam continued to develop as the deflection of the beam increased. Finally, the concrete at the compression zones was crushed, one longitudinal reinforcement bar was broken and the beam failed in flexure.

In specimens MCB3 and MCB4, which have even larger span/ depth ratios, shear cracks were also formed near the centre of each beam after the longitudinal reinforcement bars had yielded. However, these shear cracks were generally formed at much later times when the deflections of the beams were already very large and they did not develop even when the beam specimens failed. At the post-peak stage, the flexural cracks opened up quickly and eventually both MCB3 and MCB4 failed in flexure. In the case of MCB3, one longitudinal but they generally failed in a more ductile manner.

Nevertheless, all the four beam specimens could sustain a maximum shear deflection of about $50 \mathrm{~mm}$ before their loadresisting capacities dropped significantly (by about 10\%). Since the beam specimens have a clear span of $700 \mathrm{~mm}$, such a maximum deflection capacity of $50 \mathrm{~mm}$ represented a maximum drift ratio (shear deflection per clear span ratio) of $7 \%$, which is not small judging from the relatively small span/ depth ratios of the beam specimens.

\subsection{Strength and ductility}

A summary of the strength and ductility results is presented in Table 2. Since the four beam specimens had the same thickness, the same clear span and nearly the same steel ratios, the only major factor affecting the strength of the beam specimen was the depth of the beam. From the table, it can be 


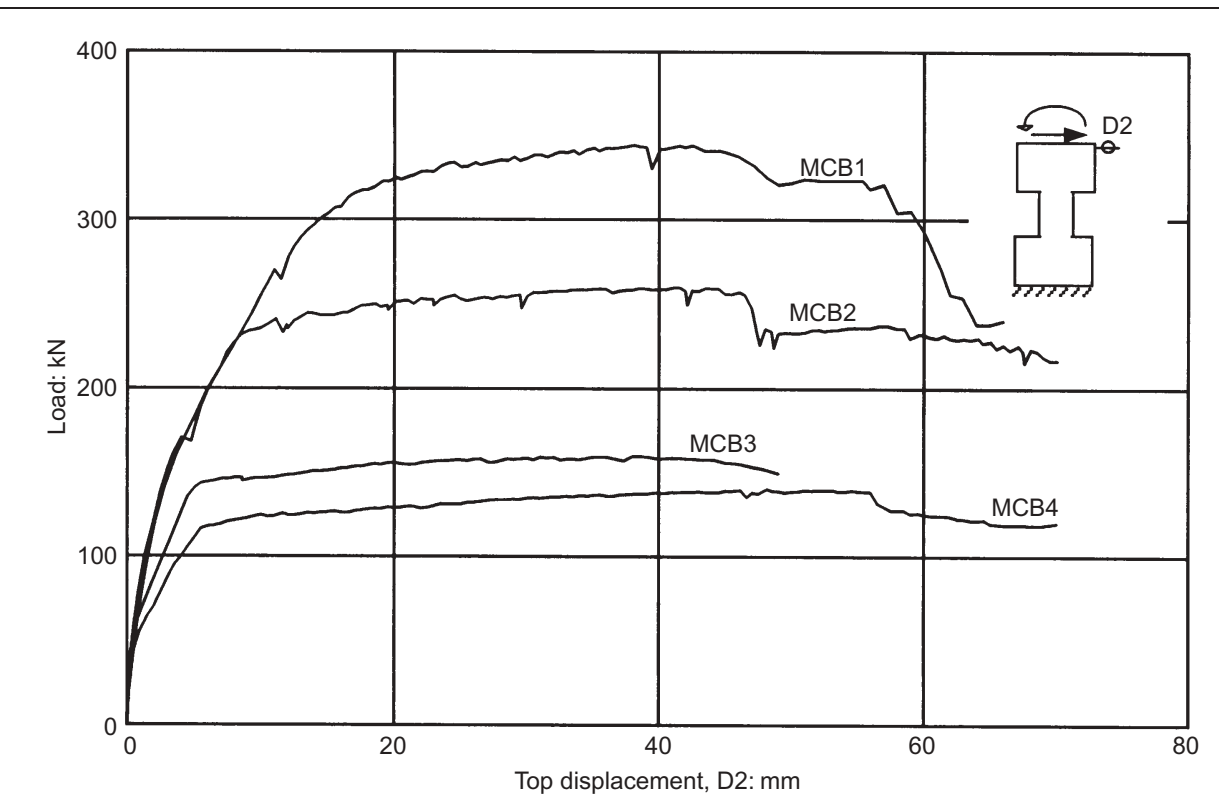

Fig. 7. Complete load-deflection curves of the beam specimens

case of beam specimen MCB3, since the test was stopped due to breakage of one longitudinal

reinforcement bar before the deflection had reached the deflection at ultimate, the deflection at ultimate was taken as the maximum deflection measured during the test. From the results tabulated in Table 2, it is seen that as the span/depth ratio increased from $1 \cdot 17$ to $2 \cdot 00$, the ductility ratio increased from $5 \cdot 7$ to $16 \cdot 8$. In those beams, which failed in flexure, ductility ratios of more than 10 were achieved. Even in the case of MCB1, which failed in shear, the ductility ratio was greater than 5 , a relatively high value for a beam failing in shear. This was because the beam specimen MCB1 actually failed in the sheartension mode, a shear failure mode accompanied by yielding of the transverse reinforcement.

\subsection{Strain distribution in longitudinal reinforcement} Figure 8 shows the variation of the axial strains in the longitudinal reinforcement with the applied shear load for the beam specimens MCB1 and MCB4. The other beam specimens MCB2 and MCB3 have similar axial

seen that the beam specimens MCB2, MCB3 and MCB4, which had relatively small depths, all failed in flexure. As the depth of the beam increased, the flexural strength of the beam also increased. When the depth of the beam increased to beyond a certain limit, as in the case of the beam specimen MCB1, the flexural strength could become so large that the shear strength of the beam would be more critical and the beam would fail in shear. It may be said therefore that the strength of a coupling beam may be governed by either the flexural strength or the shear strength depending on the span/depth ratio of the beam.

Together with the increase in strength as the depth of the beam increased, there was a decrease in ductility. In this study, the ductility of the beams was evaluated in terms of a ductility ratio, which is defined as the ratio of the deflection at ultimate to the deflection at yield. The deflection at ultimate was taken as the deflection at the post-peak stage when the load-resisting capacity had dropped to $85 \%$ of the peak load, while the deflection at yield was taken as the deflection when the longitudinal reinforcement started to yield. In the particular strains developed in their longitudinal reinforcement and thus for brevity their results are not presented. It is seen that at small applied load level, when the beams were still elastic, the axial strains developed in the longitudinal reinforcement bars corresponded to a contraflexural moment distribution along the length of the beam. The contraflexural moments acting on the beam resulted in equal end moments in the same direction (anticlockwise direction as shown in Fig. 8) at the ends of the beam and zero moment at the centre of the beam. The end moments caused the longitudinal reinforcement bars near the ends of the beam to be subjected to tension on one side and compression on the other side, while the zero moment at the centre of the beam caused the longitudinal reinforcement bars at the centre of the beam to remain unstressed, as in an ordinary beam. Hence, at the elastic stage, the coupling beams behaved like ordinary beams.

After the appearance of inclined shear cracks, however, the strain distribution in the longitudinal reinforcement bars gradually changed. Firstly, the tensile strain developed in the 


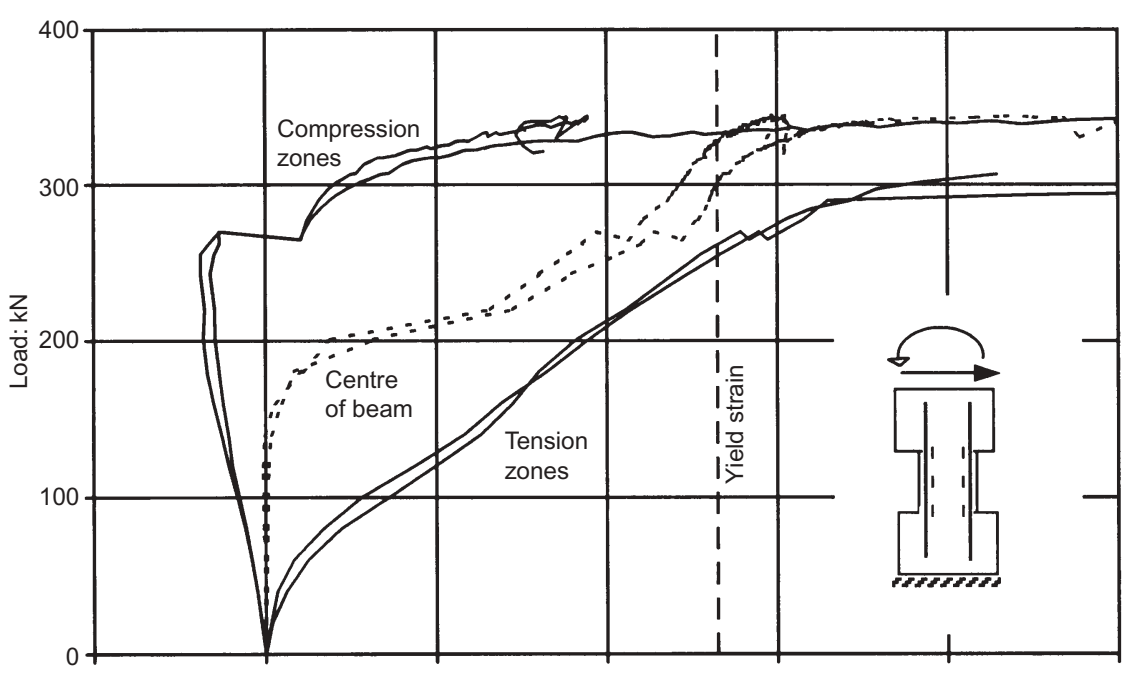

(a)

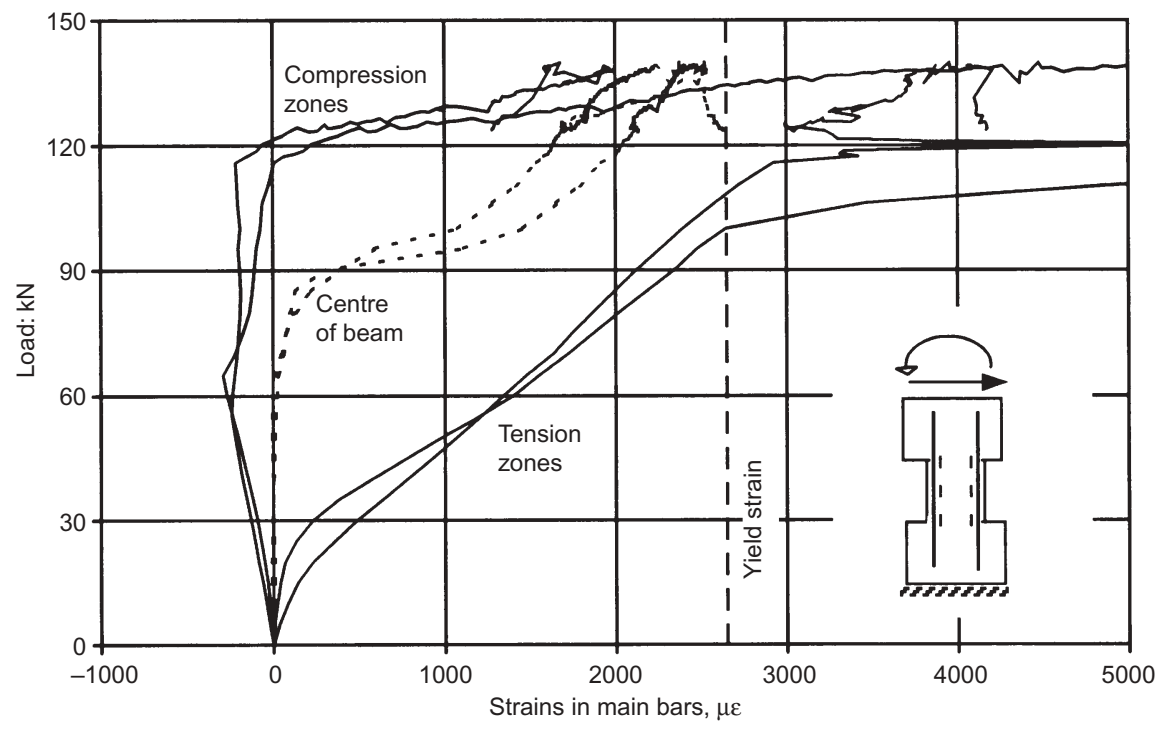

(b)

Fig. 8. Strain distribution in the longitudinal reinforcement of: (a) MCB I; (b) MCB4

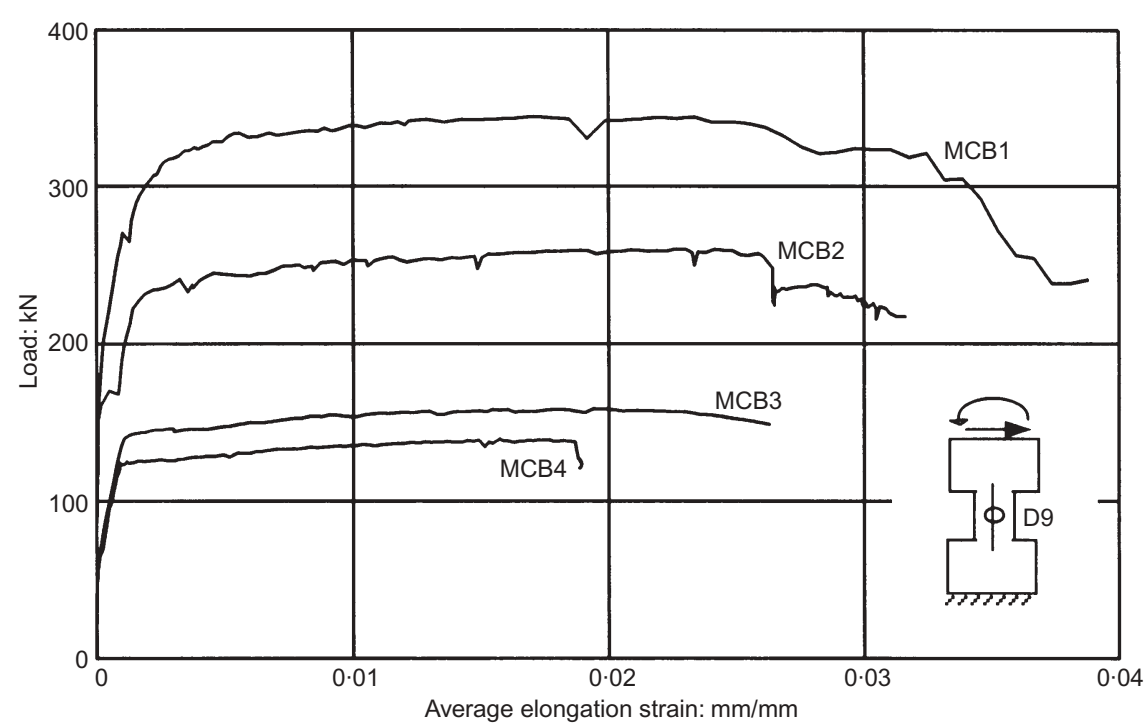

Fig. 9. Average elongation strains of the beam specimens longitudinal reinforcement bars near the ends of the beam became significantly larger than the corresponding compressive strain developed in the longitudinal reinforcement bars at the same end but opposite side of the beam. Secondly, the compressive strain in the longitudinal reinforcement bars near the ends of the beam stopped increasing and then started to decrease, causing the strain to eventually become tensile. Thirdly, significant tensile strains were developed in all the longitudinal reinforcement bars at the centre of the beam despite zero moment acting there. All these changes indicated that after the appearance of shear cracks, the coupling beams started to elongate and no longer behaved like ordinary beams.

\subsection{Axial elongation}

The axial elongation of each beam specimen had been measured by an LVDT mounted at each end to one of the two end blocks of the beam specimen. These axial elongation results are depicted in Fig. 9, where the applied shear load of each beam specimen is plotted against the average elongation strain (amount of elongation divided by gauge length) of the specimen. It can be seen from the figure that at small applied load, when the beams had not yet cracked and were still elastic, there was basically no axial elongation. However, when the applied load increased and inclined shear cracks were formed in the beams, the beams all started to gradually elongate in the axial direction. After the longitudinal reinforcement bars in the beam specimens had yielded, the axial elongations of the beams continued to increase at even faster rates. Eventually, when 
the beam specimens failed, the average elongation strains of the beam specimens reached their maximum values of $2 \cdot 0-$ $3 \cdot 5 \%$. Such elongation strains were more than sufficient to cause all longitudinal reinforcement bars to yield before the beams failed. This explains why in each beam specimen, all the longitudinal reinforcement bars were in tension throughout the whole length of the beam at a certain stage before the beam failed. The beam specimens with different span/depth ratios elongated by different amounts. Basically, the smaller the span/ depth ratio, the larger the average elongation strain when the beam failed.

The axial elongation has given the coupling beams a special characteristic that differentiated the coupling beams from the ordinary beams in frame structures, but what caused such axial elongation? From the crack patterns shown in Fig. 6, it can be seen that extensive inclined shear cracks appeared in the beams. Between the inclined shear cracks, diagonal concrete struts were formed. From a static equilibrium point of view, the transverse component of the compressive forces developed in the struts resisted the applied shear load while the longitudinal component pushed the wall panels apart causing the coupling beams to elongate. From a kinematic point of view, as the lateral deflection of the coupling beam increased, the diagonal concrete struts rotated about the compressive corners of the coupling beam thereby causing axial elongation of the coupling beam. The axial elongation due to the rotation of the diagonal concrete struts may be estimated as beam depth/beam length $x$ the lateral deflection. Because of compression shortening of the diagonal concrete struts, the actual amount of axial elongation was smaller than such estimated value. Nevertheless, this explains the observation that the smaller the span/depth ratio of the beam, the larger the amount of axial elongation.

\subsection{Local deformation at beam-wall joints}

During each test, LVDTs were installed to monitor the lateral displacements and rotations of the beam specimen at different positions along the length of the beam and also within the wall panels at different distances from the beam- wall joints. The LVDT results for the lateral displacements revealing the shear movement of the beam-wall joints and those for the rotations showing the variation of the rotation along the longitudinal axis of the beam specimen are presented in Figs 10(a) and 10(b) respectively. For brevity, only the results for specimen MCB1 are plotted in the figure.

In Fig. 10(a), the applied shear load is plotted against the deflection within the clear span of the beam (D4-D6) and against the total deflection of the beam as measured along the far end edges of the end blocks (D2). It is seen that the total deflection (D2), which included the deflection of the beam itself and the deflection due to local joint deformation, was consistently larger than the deflection within the clear span of the beam (D4-D6). The difference between D2 and (D4-D6) was actually the increase in lateral deflection of the beam due to lateral displacements of the beam-wall joints. Before reaching peak load, the increase in lateral deflection due to lateral displacements of the beam-wall joints was of the order

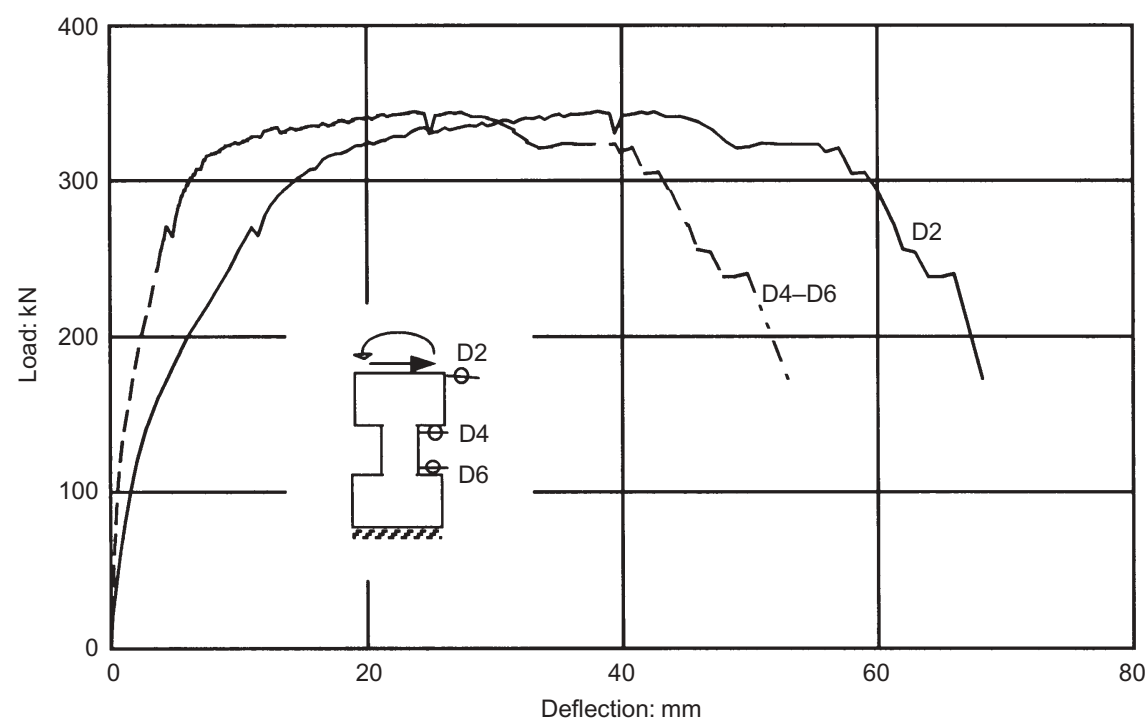

(a)

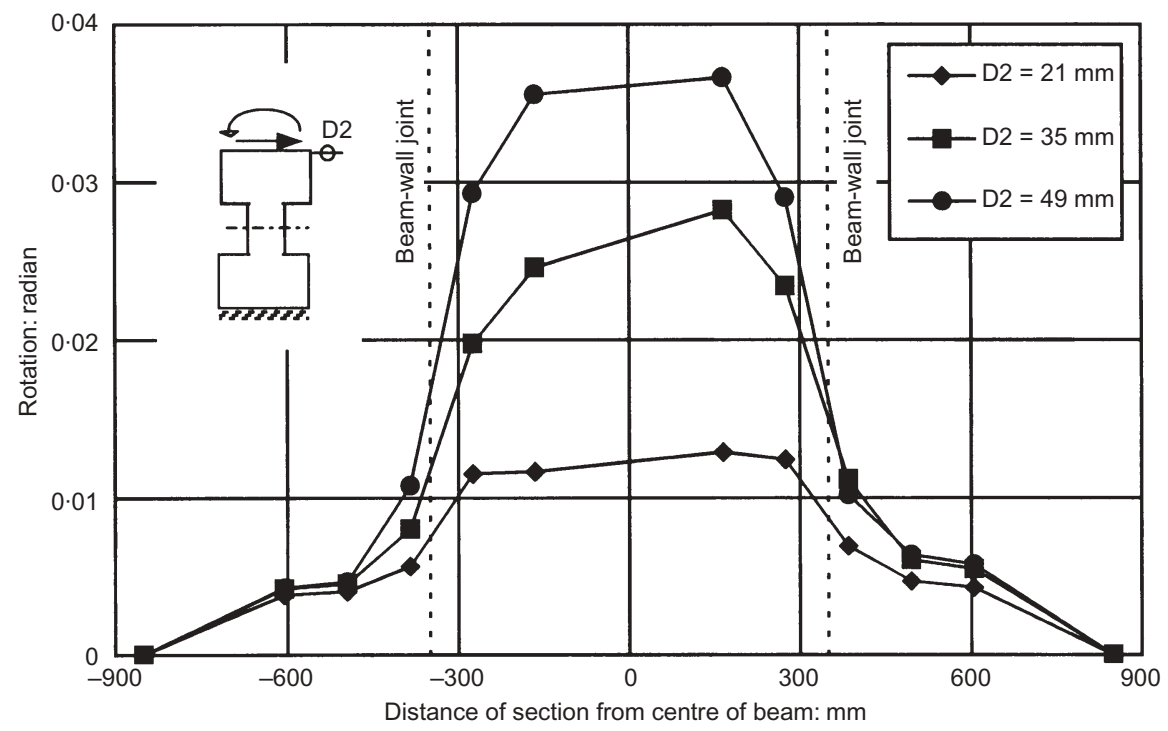

(b)

Fig. 10. Local deformation at beam-wall joints of MCB I: (a) load-deflection curves; (b) variation of section rotation along length of beam 
of 5-10 mm. After reaching peak load, the increase in lateral deflection due to lateral displacements of the beam-wall joints increased gradually to about $20 \mathrm{~mm}$ and thereafter remained constant until the beam specimen failed.

In Fig. 10(b), the rotations at various sections along the longitudinal axis of the beam are plotted against the distances of the sections from the centre of the beam. It is seen that at all loading stages, starting from the elastic to the post-peak stage, there were significant rotations at the beam-wall joints. For instance, at the post-peak stage, when the total deflection of the beam specimen was equal to $49 \mathrm{~mm}$, the rotations at the beam -wall joints were equal to approximately 0·017 radian. Since the clear span length was $700 \mathrm{~mm}$, such amounts of joint rotations had led to an increase in total deflection of the beam of about $0.017 \times 700 \mathrm{~mm}=12 \mathrm{~mm}$, which was quite substantial compared to the total deflection of the beam.

The above results revealed that the local wall deformation near the beam -wall joints caused lateral displacements and rotations of the beam-wall joints, which in turn contributed significantly to additional lateral deflection of the coupling beam. In the particular case of MCB1, at a total deflection of $49 \mathrm{~mm}$, the additional deflection due to lateral displacements of the beam-wall joints was about $15 \mathrm{~mm}$ and that due to rotations of the beam-wall joints was about $12 \mathrm{~mm}$. Added together, the additional lateral deflection of the beam due to the lateral displacements and rotations of the beam-wall joints was $27 \mathrm{~mm}$, which amounted to more than half of the total deflection of the beam.

\section{CONCLUSIONS}

A new method of testing reinforced concrete coupling beams that ensures equal end rotations of the beam specimen and takes into account the local wall deformation near the beamwall joints has been developed. Compared to previous test methods developed by others, this method can better simulate the actual displacement boundary conditions at the beam-wall joints throughout the loading history. It has been applied to test reinforced concrete coupling beams with relatively small span/depth ratios and proven to be suitable for studying the post-peak behaviour of coupling beams.

The test results revealed that conventionally reinforced concrete coupling beams with span/depth ratios less than $2 \cdot 0$ differ from ordinary concrete beams in the following ways.

(a) After the appearance of inclined cracks, a short coupling beam would gradually elongate in the axial direction and eventually all the longitudinal reinforcement bars would be in tension along the whole length of the beam. The axial elongation may amount to more than $2 \%$ of the clear span length and is larger at a smaller span/depth ratio.

(b) An area of zero axial stress does not exist in a short coupling beam even at the centre of the beam where the bending moment is zero.

(c) The local wall deformation near the beam-wall joints would cause significant lateral displacements and rotations of the beam - wall joints which in turn could lead to substantial increase in the lateral deflection of the coupling beam if it is relatively short. In a very short coupling beam with a span/depth ratio less than $1 \cdot 2$, the additional deflection due to local joint deformation could amount to more than $50 \%$ of the total deflection of the beam.

Complete load-deflection curves have been obtained by conducting the tests under displacement control. From these curves, it is seen that despite their relatively small span/depth ratios, the coupling beams tested could sustain a maximum deflection of about 7\% of the clear span length before their load-resisting capacities dropped significantly. Furthermore, in those beams which failed in flexure, the ductility ratios were all greater than 10. Even in the beam specimen which failed in shear, a ductility ratio of greater than 5 was achieved. These ductility ratios were larger than expected. One possible reason was that the local joint deformation generally caused larger increase in the lateral deflection of a coupling beam at the post-peak stage. The non-linear behaviour of the beam-wall joints seems to have some effects on the ductility of a coupling beam.

\section{ACKNOWLEDGEMENT}

The financial support from the Research Grants Council of Hong Kong (Project Reference: HKU 7005/00E) for the research reported herein is gratefully acknowledged.

\section{REFERENCES}

1. PaUlay T. An elasto-plastic analysis of coupled shear walls. ACI Structural Journal, 1970, 67, No. 11, 915-922.

2. GLüCK J. Elasto-plastic analysis of coupled shear walls. Journal of Structural Division, ASCE, 1973, 99, No. ST8, 1743-1760.

3. FinTEL M. and GHISH S. K. Case study of aseismic design of a 16-storey coupled shear wall structure using inelastic dynamic analysis. ACI Structural Journal, 1982, 79, No. 3, 110-118.

4. Fenwick R. C. and Paulay T. Mechanisms of shear resistance of concrete beams. Journal of Structural Division, ASCE, 1968, 94, No. ST10, 2325-2350.

5. ARISTIZABAL-OchoA J. D. Seismic behavior of slender coupled wall system. Journal of Structural Engineering, ASCE, 1987, 113, No. 10, 2221-2234.

6. PAULAY T. Coupling beams of reinforced concrete shear walls. Journal of Structural Division, ASCE, 1971, 97, No. ST3, 843-862.

7. KWAN A. K. H. and ZHAO Z. Z. Reinforced concrete coupling beams: their differences from ordinary beams. Proceedings of the 7th International Conference on Enhancement and Promotion of Computational Methods in Engineering and Science EPMESC VII, Macao, 1999, 1, 581-588.

8. KWAN A. K. H. and ZHAO Z. Z. Nonlinear behaviour of reinforced concrete coupling beams. Proceedings of the 5th International Conference on Tall Buildings, Hong Kong, 1998, 1, 410-415.

9. WANG W. H., FU X. D. and Ni Y. Behavior of ceramic aggregate concrete coupling beams in shear wall structure under reversed cyclic loading. Journal of Building Structures, 1992, 13, No. 1, 71-78.

10. Tassios T. P., Moretti M. and Bezas A. On the behavior and ductility of reinforced concrete coupling beams of shear walls. ACI Structural Journal, 1996, 93, No. 6, 711-720.

11. PAUlay T. and BinNEY J. R. Diagonally reinforced coupling beams of shear walls. ACI Special Publication SP-42: 
Shear in Reinforced Concrete, 1974, 2, American Concrete Institute, Detroit, pp. 579-598.

12. LI G. W. and LI W. M. The strength and ductility of the reinforced concrete coupling beam under reverse cyclic loading. Proceedings of the 8th National Conference on High-rise Building Structures, Tunxi, China, 1984, 5, 14-7-1.

13. KWAN A. K. H. Local deformations and rotational degrees of freedom at beam-wall joints. Computers \& Structures, 1993, 48, No. 4, 615-625.
14. Barney G. B., ShiU K. N., Rabbat B. G., Fiorato A. E., Russell H. G. and CoRley W. G. Behavior of coupling beams under load reversals. Research and Development Bulletin RD068.01B, Portland Cement Association, USA, 1980.

15. Igarashi H., IzUmita S., TaKeuchi M., Arai M., FuJisawa M. and MurakAMI H. Deformation capacity of reinforced concrete beams used high strength concrete and reinforcement. Proceedings of the 10th World Conference on Earthquake Engineering, Madrid, 1992, 3077-3082.

Please email, fax or post your discussion contributions to the secretary: email: lyn.richards@ice.org.uk; fax: +44 (0)20 7799 I325; or post to Lyn Richards, Journals Department, Institution of Civil Engineers, I-7 Great George Street, London SWIP 3AA. 